\title{
STATISTICAL EDUCATION: FOCUSING ON THE LEARNER
}

\author{
ALAIN BIHAN-POUDEC \\ LAREF (Université Catholique de l'Ouest, Angers, France) \\ alain.bihan-poudec@uco.fr
}

\begin{abstract}
For over thirty years, statistical education has fought for a "pedagogy of proximity." But if this seems to bring greater success, it does not guarantee the understanding of statistical concepts. An analysis of an experiment by Gattuso \& Mary (2003, 2005), and an observational study made by the author, highlight the phenomenon of "cognitive isolation." This underlines the importance of the learners' views of statistics. The work of Reid and Petocz (2002) corroborates this and provides more insight into the necessity of an exogenous disturbance to learning so that it is fully realized. Methodologically, it emerges that qualitative methods have their full place in statistical education research, including as an opportunity to reassess the research objectives.
\end{abstract}

Keywords: Statistics education research; Cognitive isolation; Exogenous disturbance; Problematization

\section{EXTENDED SUMMARY}

Prepared by Peter Petocz

Statistics attracts little enthusiasm, particularly among students in the social sciences. To address this problem, a pedagogy of proximity - teaching closer to the students - has been developed since the 1980s. This focuses on data, activity, and technology at the expense of theory, reading, and calculation. The data used are close to the students' experience and their home discipline, and may even be collected by the students. "Introduction to Statistics" has given way to "Statistics applied to ...," and the resulting approach is flourishing. But is it resulting in improvement? Certainly in terms of interest and motivation, but does focusing on data closer to the students guarantee better understanding? This is harder to establish. Students may prefer a surface approach to learning, based on texts, examples, exercises, and exams. Statistics teachers point out that students have difficulties using the techniques they have studied: Their statistical methods may be inappropriate, and their written explanations sketchy.

\section{TWO PROBLEMATIC SITUATIONS}

Mary and Gattuso (2003, 2005) reported on an experiment carried out with 600 secondary students in Quebec in years 2-4 (ages 13-16). They posed problems concerning average, and supposed that the context involving grades (notes) would be easiest because it was more familiar to the students than those involving weights (poids) or ages. For example, the question on grades: "Claude took 10 music tests. For the 8 before Easter he got an average of 80, and for the 2 after, an average of 40 . What is his average result in music? To progress he needs to get a total of at least 700: Did he do

Statistics Education Research Journal, 9(2), 104-107, http://www.stat.auckland.ac.nz/serj (C) International Association for Statistical Education (IASE/ISI), November, 2010 
this?" However, Table 1 shows that only in year 4 was there a higher pass rate for the question involving grades.

Provoked by these results, we asked the same questions, including an introductory question, of a French family of four children. The introductory question was: "I got 14/20 in a test, then 3/20 and 7/20. How much do I need on the fourth test to get an average of $10 / 20$ ?" The details of the interviews with the four children are given, and their answers to the introductory question are summarized here.

Corentin (12; junior secondary school): He adds the first three results and gets 24 . He then adds on 14, and when asked why, replaces it with 15 to get a sum of 39 , and then finally with 16 , when he says it would have been better to subtract the total of the first three from 40.

Maëlys (16; senior secondary school): She adds the first three results and divides by 3 to get $8 / 20$. Then she writes down the formula $8 / 20+x / 20=10 / 20$ and comes to a halt.

Anne-Laure (almost 18; first year university): Quick response of 16, explaining "14 gives me 4 points ahead, 3 and 7 give me 10 points behind, which is 6 points behind overall, so I need 6 points, so 16."

Joévan (8; primary school): "What is average?" I show him the example of $15 / 20+5 / 20=20 / 40=10 / 20$, and then $15 / 20+5 / 20+10 / 20=30 / 60$ to which he gives the answer $10 / 20$. Then I put the question as $14 / 20+3 / 20+7 / 20+? / 20=10 / 20$. He tells me to write $24+? / 80$ and to replace ? by 16 .

Again, the results are surprising as the youngest seem to do better. Both the oldest girls asked (in the other questions) whether there was a "trap." The eldest, Anne-Laure, used a formula to find the results, though not the usual formula, but rather the property that the mean is the number from which all the deviations sum to zero. Her sister got lost in the calculations. The two younger ones obtained correct results without the benefit of formulas. It seems that knowing these formulas was a hindrance rather than a benefit, and-paradoxically - the mathematical formulation seems more important than the context. Of course, the notion of average is often used informally as well as mathematically, and there is no guarantee that these students had experienced any pedagogy of proximity.

\section{DISCUSSION}

Teaching statistics is differentiated from teaching mathematics by linking the mathematical techniques to relevant context. Though this may lead to increased interest from learners, it doesn't necessarily lead to better understanding. A common failing is that students do not use the real context to critique their statistical conclusions, divorcing the theoretical aspects from the practical. We could speak here of cognitive isolation, using the Freudian term isolation that represents a defense mechanism separating unwanted thoughts or behavior from the rest of a subject's existence. This isolation suggests the automathismes described by Baruk (1977) — facing problem solving in mathematics, some students invoke mathematical processes without noticing that they are inadequate for the problem at hand. It also includes problems with selection skills, when students are unable to select appropriate statistical tests or procedures, though they are familiar with them. Interestingly, such isolation does not seem to occur out of the school context. Although 
we would expect that academic knowledge could be used to solve statistical problems, this knowledge is often less effective than common sense, which is not seen as statistical knowledge by its users.

This distinction between academic knowledge and common sense is expanded by research conducted on students' views of statistics (Reid \& Petocz, 2002). They identified six conceptions, the first three focusing on techniques (numerical and statistical), the next two on data (analysis and interpretation, and their use in understanding real situations), the final one on making sense of the world and developing personal understandings. The phenomenon of cognitive isolation seems to occur only in the first three conceptions, where the focus is exclusively on technique used for itself. Note that the conceptions are hierarchical, and the later, broader ones include the earlier, narrower ones. They bring to mind the evolutionary mechanisms of passage of cognitive development identified by Piaget and Garcia (1983) - the first stage where the development includes what was previously developed, and the second stage where it goes beyond the previous knowledge to the study of relations or transformations. Xypas (2005) points out the necessity for an exogenous disturbance in learning so that the learner values the struggle to learn. Note, however, that Reid and Petocz did not conduct a longitudinal study and do not claim their conceptions as developmental stages, pointing out that all conceptions were present at each year of study.

\section{CONCLUSION AND OUTLOOK}

Based on this desire to teach statistics closer to the students, we asked whether this led to better understanding of the discipline. Observations show that this is not always so, and that the use of statistical methods may give worse results than common sense. Vallet (2005) pointed out that the main impediment to learning statistics in the social sciences was the disembodied approach that conflicts with the main interest of these studentspeople and the experiences of people. No doubt teachers point to the importance of the discipline and its applications, but the focus is on exposition and transmission. Statistics itself is the starting point for the teacher, whereas for the student it is important only as far as it is part of her own world. The required disturbance is not likely to be found in a problem given to a student, but in the reason why solving the problem is important to her; and these reasons are not to be found in the discipline itself.

The general process identified by Piaget and Garcia could be applied to the epistemological question of the construction of knowledge about the construction of knowledge. To investigate the growth of statistical knowledge, we could investigate the conditions for moving from one conception to the next. Further, to investigate the validity of a theory we should add to the classical ideas of internal and external validity the notion of comparative validity-how a theory accounts for other theories with its concepts and history. And what would this say about our theory of learning?

Our final remark refers to the role of qualitative approaches in the methodology of educational research in statistics. Though it may seem reasonable a priori that such research should be statistically based, there are many examples where qualitative methods are complementary to quantitative. Examples include situations where the meaning of a word in a questionnaire is crucial, and study of the relationship between ways of learning and performance in statistics. The qualitative approach aims to understand the ways of behaving rather than the behavior itself, and to include the affective aspects of learning statistics. Quantitative approaches lend a special status to the researcher, privileging the discipline and its logic. The clinical or phenomenological approach, by contrast, gives the opportunity to see the subject's own world appear, to invite the researcher into a unique 
position where he suspends his own judgment in order to view another's perceptions of the same object. A researcher in statistics education must admit that the way that students understand the subject is quite likely to be different from his own. A paradoxical situation for the researcher-his research aims to know its object better, but in order to do this, he must put it aside! In so doing, he has the opportunity of re-assessing his view of the research objectives.

\section{REFERENCES}

Baruk, S. (1977). Échec et Maths (3rd ed.). Paris : éd. du Seuil, coll. Point, nº11.

Mary, C., \& Gattuso, L. (2003, December). L'influence des grandeurs impliquées sur la résolution d'un problème de moyenne. Presentation at the Colloque EMF 2003, Tozeur, Tunisie.

Mary, C., \& Gattuso, L. (2005). Trois problèmes semblables de moyenne pas si semblables que ça ! L'influence de la structure d'un problème sur les réponses des élèves. [Three similar mean problems: are they really that similar? Research on the influence of the structure of the problem on students' responses]. Statistics Education Research Journal, 4(2), 82-102.

[Online: http://www.stat.auckland.ac.nz/ iase/serj/SERJ4(2) mary gattuso.pdf]

Piaget, J., \& Garcia, R. (1983). Psychogenèse et Histoire des Sciences. Paris : Flammarion, coll. Nouvelle bibliothèque scientifique.

Reid, A., \& Petocz, P. (2002). Students' conceptions of statistics: a phenomenographic study. Journal of Statistics Education, 10(2).

[Online: http://www.amstat.org/publications/jse/v10n2/reid.html]

Vallet, L.-A. (2005). Réflexions libres à partir d'une pratique d'enseignement de la statistique en sciences humaines et sociales. In A. Bihan-Poudec, C. Chevallier-Gaté, J.-P. Gaté, \& N. Zendrera. (Eds.), Mesurer : actes du symposium «pédagogie de la statistique à l'université ». Éduquer, 14, 103-110.

Xypas, C. (2005, May). Poser et construire le problème : l'apport de Piaget entre pragmatisme et constructivisme. Paper presented at the 73rd conference of l'Association Francophone pour le Savoir (ACFAS), Chicoutimi, Québec.

ALAIN BIHAN-POUDEC Institut des Sciences de la Communication et de l'Éducation d'Angers Laboratoire de Recherche en Éducation et Formation Université Catholique de l'Ouest

BP 10801

49008 Angers cedex 01

France 